\title{
O Levantamento Preliminar na selação de Questões Sociocientíficas: o exemplo do areial em Olivença/BA
}

DOI 10.26512/Ic.v24i0.19709

Valéria Bonfim
Universidade Estadual de Santa Cruz
leria.bonfim@gmail.com

Josenilda Assunção

Universidade Estadual de Santa Cruz josylimapedro@gmail.com

Manuela Gomes Bomfim Universidade Estadual de Santa Cruz manuelag.bomfim@gmail.com

Jeruza Rocha Lima Arcanjo Universidade Estadual de Santa Cruz jeruzapei@hotmail.com

Simoni Tormohlen Gehlen Universidade Estadual de Santa Cruz stghelen@gmail.com

\section{Resumo}

Estudos têm evidenciado um significativo crescimento de trabalhos da área da Educação em Ciências que utilizam Questões Sociocientíficas (QSCs), principalmente para elaboração de propostas didático-pedagógicas, porém, nem sempre explicitam os critérios para a escolha dessas QSCs a serem trabalhadas em sala de aula. Assim, investigam-se critérios de escolha das QSCs tendo como parâmetro aspectos do Levantamento Preliminar - primeira etapa da Investigação Temática (Freire, 1987) -. O estudo foi desenvolvido no contexto de processo de formação de professores, tendo como referência a Investigação Temática, 
realizado em uma escola localizada no distrito de Olivença, município de Ilhéus/ BA. As informações foram obtidas mediante blogs, sites de notícias da região e de conversas informais com moradores da comunidade de Olivença, e a análise foi realizada por meio da Análise Textual Discursiva com foco na categoria "o papel do Levantamento Preliminar na seleção de QSCs". Dentre os resultados obtidos, destaca-se, que por meio das etapas do Levantamento Preliminar, identificou-se a controvérsia Areial, relacionada com a extração de areia no distrito de Olivença e que apresenta características das QSCs. Constatou-se que o Levantamento Preliminar pode ser um dos critérios de seleção e legitimação de uma QSC referente a uma questão local, em que a discussão pode ser ampliada para contextos globais. Essa QSC, ao ser trabalhada em sala de aula, pode contribui para uma ação social responsável dos educandos de uma comunidade localizada no município de Ilhéus/BA.

Palavras-chave: QSC, Levantamento Preliminar, Educação em Ciências, Paulo Freire

\section{Abstract}

Studies have evidenced a significant growth of works in the area of Science Education that use Socio-Scientific Questions (QSCS), mainly for the elaboration of didacticpedagogical proposals, but without specifying the criteria for choosing these QSCs to be worked in the classroom. Thus, the criteria for choosing the QSCs are investigated, taking as a parameter aspects of the Preliminary Survey- the first stage of the Thematic Research - The study was developed in the context of a teacher training process, with reference to the Thematic Research, carried out in a school located in the district of Olivença, municipality of Ilhéus / BA. The information was obtained through blogs, news sites of the region and informal conversations with residents of the community of Olivença, and the analysis was carried out through Discursive Textual Analysis focusing on the category "the role of Preliminary Survey in the selection of QSCs". Among the results, it is worth noting that through the Preliminary Survey stages, the Areial controversy was identified, related to sand extraction in the district of Olivença and presenting characteristics of the QSCs. It was verified that the Preliminary Survey can be one of the criteria of selection and legitimation of a QSC referring to a local question, in which the discussion can be extended to global contexts. This QSC, when being worked in the classroom, can contribute to a responsible social action of the students of a community located in the municipality of Ilhéus / BA.

Keywords: QSC, Preliminary Survey, Education in Sciences, Paulo Freire.

\section{Resumen}


Los estudios han evidenciado un significativo crecimiento de investigación del área de la Educación en Ciencias que utilizan Cuestiones Sociocientíficas (CSCs), principalmente para la elaboración de propuestas didáctico-pedagógicas, sin embargo, sin explicitar los criterios para la elección de esas CSCs a ser trabajadas en el aula. Así, se investigan criterios de elección de las CSCs teniendo como parámetro aspectos del Levantamiento Preliminar - primera etapa de la Investigación Temática (Freire, 1987). El estudio fue desarrollado en el contexto de proceso de formación de profesores, teniendo como referencia la Investigación Temática, realizado en una escuela ubicada en el distrito de Olivença, municipio de Ilhéus / BA. La información fue obtenida mediante blogs, sitios de noticias de la región y de conversaciones informales con moradores de la comunidad de Olivenza, y el análisis fue realizado por medio del Análisis textual Discursivo con foco en la categoría "el papel del Levantamiento Preliminar en la selección de CSCs". Entre los resultados, se destaca que por medio de las etapas del Levantamiento Preliminar se identificó la controversia Areial, relacionada con la extracción de arena en el distrito de Olivenza y que presenta características de las CSC. Se constató que el Levantamiento Preliminar puede ser uno de los criterios de selección y legitimación de una CSC referente a una cuestión local, en la que la discusión puede ser ampliada para contextos globales. Esta CSC, al ser trabajada en el aula, puede contribuir a una acción social responsable de los educandos de una comunidad ubicada en el municipio de Ilhéus / BA.

Palabras clave: CSC, Levantamiento Preliminar, Educación en Ciencias, Paulo Freire

\section{Résumé}

Des études ont démontré une croissance significative des travaux dans le domaine de l'éducation scientifique qui utilisent des questions socio- scientifiques (QSQs), principalement pour l'élaboration de propositions didactiques-pédagogiques, mais sans préciser les critères de choix de ces QSC à travailler en classe. Ainsi, les critères de choix des QSC sont étudiés, en prenant comme paramètres les aspects de l'enquête préliminaire-la première étape de la recherche thématique (Freire, 1987). L'étude a été développée dans le cadre d'un processus de formation des enseignants, en référence à la recherche thématique, réalisée dans une école située dans le district d'Olivença, municipalité d'Ilhéus / BA. L'information a été obtenue à travers des blogs, des sites d'information de la région et des conversations informelles avec des résidents de la communauté d'Olivença, et l'analyse discursive a porté sur la catégorie "le rôle de l'enquête préliminaire dans la sélection des QSCs». Parmi les résultats, il convient de noter qu'à travers les étapes de l'enquête préliminaire, la controverse Areial a été identifiée, liée à l'extraction de sable dans le district d'Olivença et présentant des caractéristiques des QSCs. II a été vérifié que l'enquête préliminaire peut être 
I'un des critères de sélection et de légitimation d'un QSC se référant à une question locale, dans laquelle la discussion peut être étendue à des contextes globaux. Ce QSC, lorsqu'il est travaillé en classe, peut contribuer à une action sociale responsable des étudiants d'une communauté située dans la commune d'Ilhéus / BA.

Mots-clés: QSC, Enquête préliminaire, Science Education, Paulo Freire

\section{Introdução}

Pensar em educação, especificamente no contexto escolar, com olhar voltado para sala de aula, remota atenção à questão da conscientização cidadã como possibilidade de consolidar a participação social. Até porque a escola numa vertente humanizadora necessita apresentar sentido e significado aos conteúdos e conceitos que serão trabalhados em sala de aula para uma formação voltada para cidadania, emancipação e transformação social (Delizoicov, Angotti \& Pernambuco, 2002; Santos, 2007; Auler \& Delizoicov, 2015).

Entretanto, a escola precisa avançar diante dos desafios que emergem dos diversos setores da sociedade (cultural, econômica, social, políticas, tecnológicas, etc.) tendo em vista vencer a dimensão fragmentária do saber por uma percepção global do conhecimento, o que propiciará um senso de consciência do sujeito na tomada de decisões (Fazenda, 1993). Ao referir-se à importância da criticidade, Freire (1996) salienta que "constato não para me adaptar, mas para mudar. Constatando, nos tornamos capazes de intervir na realidade, tarefa muito mais complexa e geradora de novos saberes do que simplesmente nos adaptar a ela" (Freire, 1996, p.77). O indivíduo tem o direito de aprender conscientemente, indo além de conhecimentos prontos para que seja capaz de participar ativamente das decisões no campo político e social que interferirão na sua vida e das gerações futuras (Bazzo, 1998).

Ademais, o conhecimento científico e tecnológico vem produzindo avanços que promovem parte das transformações que ocorrem na sociedade e um dos grandes desafios da escola é instigar o educando a localizar os problemas que afetam a humanidade, integrando os conhecimentos na busca de compreensões e soluções para o contexto social. Pinheiro (2007, p. 155) afirma que é importante "despertar no aluno a curiosidade, o espírito investigador, questionador e transformador da realidade". Uma das formas de se desenvolver esse espírito investigativo no estudante é por meio da abordagem de Questões Sociocientíficas (QSCs) em sala de aula, que é uma situação problema que afeta os membros de uma determinada comunidade possibilitando a reflexão e tomada de decisões dos sujeitos envolvidos nessa problemática (Ratcliffe, 
2009; Reis, 2009; Martínez, 2014).

Essas QSCs são selecionadas, por exemplo, tendo como parâmetro algumas características definidas por Ratcliffe (2009), como: afetar direta ou indiretamente os contextos ambientais e sociais tanto em um âmbito local como global; partir de uma problemática que gere controvérsias e opiniões diversas entre os sujeitos envolvidos nela; ser divulgado nos meios de comunicação e ter fundamentação científica que podem ser explicadas por meio das ciências naturais ou de outras ciências.

Sousa e Gehlen (2017) observaram que houve um crescimento no número de trabalhos no Brasil que discutem a abordagem de QSCs nos últimos anos, principalmente no que se refere à elaboração de propostas didático-pedagógicas. Apesar disso, as autoras chamam a atenção para a necessidade, no contexto brasileiro, de maiores sistematizações acerca das características das QSCs e enfatizam a importância de "mais discussões relacionadas ao desenvolvimento de propostas nessa perspectiva, vislumbrando maior consenso quanto aos critérios adotados na seleção dessas questões e ao papel desempenhado por elas no processo educativo" (Sousa \& Gehlen, 2017, p. 18).

Baseada na relação entre QSC e o contexto dos educandos, uma possibilidade para a identificação dessas questões pode ser o processo de Investigação Temática, proposto por Paulo Freire, para a obtenção de Temas Geradores e adaptado por Delizoicov $(1982 ; 1991)$ para a educação formal. Nesse sentido, investigam-se critérios de escolha das QSCs tendo como parâmetro aspectos do Levantamento Preliminar - primeira etapa da Investigação Temática. Para tal, utilizam-se as informações obtidas durante um processo formativo de professores, pautado na Investigação Temática, realizado no distrito de Olivença, município de Ilhéus/BA.

\section{Questões sociocientíficas (QSCs) na Educação em Ciências}

Para Martínez e Lozano (2013), as chamadas QSCs abordadas nas pesquisas na área de Educação em Ciências nos últimos anos são parte de uma extensão e recontextualização da abordagem Ciência, Tecnologia, Sociedade e Ambiente (CTSA), visto que, muitas "das suas intenções fazem referência à formação do cidadão, à compreensão da natureza da Ciência e da Tecnologia (C\&T), alfabetização científica, análise ética e moral entre outros aspectos que fazem parte da ideologia da CTSA" (Martínez \& Lozano, 2013, p. 25). Pode-se compreender, com base em Martínez (2012), que abordar QSCs em sala de aula torna o currículo de ciências significativo, na perspectiva CTSA, pois pode possibilitar o comprometimento e responsabilidade social do profissional da educação.

Para Martínez (2012), as QSCs abrangem controvérsias públicas que são discutidas 
a todo instante nas mídias. Elas envolvem aspectos políticos, éticos e morais e, consequentemente, têm fortes impactos globais. São exemplos apresentados pelo autor questões que envolvem aspectos, como aquecimento global, transgênicos, produtos de beleza, poluição, energias alternativas, armas nucleares e biológicas, uso de produtos químicos, clonagem, experimentação com uso de animais, manipulação do genoma de seres vivos, fertilização in vitro, manipulação de células-tronco, desenvolvimento de vacinas e medicamentos, efeitos adversos da utilização da telecomunicação, entre outras. Esses aspectos mostram que as QSCs resultam de aspectos sociais, políticos e éticos comumente envolvidos em assuntos públicos provenientes do progresso científico e tecnológico. Isso implica, portanto, em opiniões públicas e, consequentemente, na tomada de decisão dos cidadãos, como afirmam Martínez et al. (2011):

O exercício da cidadania somente se desenvolverá plenamente em uma sociedade legitimamente democrática, que deve fornecer à maioria dos cidadãos sua participação efetiva no poder. Embora a participação real seja um ideal que ainda não se concretizou, é necessária a continuação do desenvolvendo de processos de formação que contribuam para o enriquecimento dos sujeitos na ação de sua cidadania (Martínez et al., 2011, p.2).

A partir da perspectiva de Martínez e colaboradores, compreende-se que quando o professor possibilita os estudantes exercerem sua cidadania frente às questões de grande abrangência como as QSCs, eles participam efetivamente da tomada de decisão. Para que isso ocorra, os autores salientam a necessidade da continuidade do desenvolvimento de processos de formação de professores, pois estes têm muito a contribuir com a formação cidadã desses educandos.

Martínez e Carvalho (2012) evidenciam no contexto da formação de professores de Ciências a necessidade de abordar QSCs que favoreçam processos de tomada de decisão nos estudantes da educação básica, possibilitando uma mudança no que se refere às estratégias didáticas que, por sua vez, estruturam e fundamentam as escolhas dos estudantes. Martínez e Carvalho (2012) também salientam a importância de considerar aspectos culturais, tanto da escola como dos estudantes, capazes de influenciar diretamente nas suas escolhas diante da sociedade, pois:

A tomada de decisão no ensino de ciências abrange o desenvolvimento de habilidades dos estudantes para realizarem suas próprias escolhas e a consideração da cultura dos estudantes, que influencia a forma como eles tomam suas próprias decisões. A discussão sobre QSCs em sala de aula parece oferecer melhores possibilidades para que os estudantes desenvolvam habilidades de pensamento crítico e melhorem a tomada de decisão (Martínez \& Carvalho, 2012, p. 730).

Os autores chamam a atenção para a questão cultural dos estudantes que tem forte influência na tomada de suas decisões particulares. As QSCs envolvem a formação das opiniões e escolhas dos estudantes, assim como dos juízos pessoais e sociais e, como consequência, implicam nos valores e aspectos éticos e relacionam-se com problemas 
sociais de ordem local, nacional e até global (Ratcliffe \& Grace, 2003).

Em se tratando das controvérsias envolvidas nas discussões públicas sobre QSCs, estas, por sua vez, tendem a exigir dos cidadãos certos conhecimentos e capacidades para que os mesmos consigam avaliar, responsavelmente, problemas científicos e tecnológicos na sociedade (Martínez \& Carvalho, 2012). Para Reis (2009), as controvérsias surgem a partir de questionamentos das pessoas envolvendo juízos de valor. Assim, uma vez que se trata de questões de valores, uma controvérsia não deve ser resolvida recorrendo apenas a fatos, vivências ou dados empíricos. Segundo o autor, existem diferentes controvérsias, tais como: controvérsias científicas: são conflitos e competições existentes dentro da instituição científica, em que um cientista busca argumentos para contrariar as hipóteses dos seus oponentes; controvérsias sociocientíficas: são as propostas científicas e tecnológicas que perpassam o meio científico chegando a desencadear fortes reações na sociedade, abarcando questões relativas às interações ciência, tecnologia e sociedade, dividindo opiniões entre a comunidade científica e a sociedade em geral; controvérsias socioambientais: são aquelas que envolvem "cientistas, decisores políticos e grupos de cidadãos" (Reis, 2009, p. 10), expondo suas diferentes percepções em relação, por exemplo, ao impacto ambiental de algum empreendimento.

Em uma sociedade democrática, o cidadão goza de plenos direitos de discutir, decidir ou resolver problemas, a depender das circunstâncias e do nível de argumentação sobre as questões em discussão (Reis, 2009). Para que haja qualquer participação significativa do cidadão nesses tipos de discussões, há a necessidade de certo grau de familiaridade com as situações em foco. Assim, a qualidade do pensamento, argumentação e da crítica do cidadão dependem, exclusivamente, da sua compreensão sobre tais controvérsias (Reis, 2009).

Partindo do pressuposto de que os cidadãos precisam ser orientados "a encarar a controvérsia convictos do seu direito de formular opiniões e de tomar decisões e não na expectativa de que qualquer autoridade possa decidir e resolver em seu lugar" (Reis, 2009, p. 14), é que os professores de Ciências, participantes de processos formativos específicos, preocupados com a formação cidadã dos seus estudantes, têm se comprometido em abordar o conhecimento científico de forma a potencializar o desenvolvimento cognitivo desses estudantes, para uma participação crítica na sociedade frente às controvérsias (Reis, 2009; Martínez \& Lozano, 2013).

Conforme destacado por Sousa e Gehlen (2017), há necessidade de melhor definir os critérios adotados para a seleção de QSCs. Martínez (2014) apresenta algumas características para as QSCs, baseadas em estudos de Ratcliffe e Grace (2003), que podem contribuir acerca dos critérios adotados como escolha para uma QSC, tais como: baseiam-se na ciência (geralmente em áreas que estão nas fronteiras do conhecimento científico); são divulgadas em meios de comunicação que possuem bastante visualização; enfrentam problemas globais e locais; abrangem a formação de 
opiniões e a realização de escolhas nos níveis pessoal e social; apresentam uma lacuna; cobrem análises de custo e benefício em que os riscos interagem com os valores, além de poder exigir alguma compreensão de probabilidade e risco; podem incluir considerações sobre sustentabilidade e abrangem valores e raciocínio ético.

Além dessas características, Martínez (2014) chama a atenção para a necessidade da abordagem das QSCs nas aulas de Ciências estar associada a conceitos, produtos e procedimentos científicos, em que o estudante deve ter a oportunidade de examinar as causas e consequências, as vantagens e desvantagens, os prós e os contras dessas questões. Logo, trabalhar essas questões em sala de aula requer algumas implicações do tipo:

Compreender os conceitos envolvidos, sejam eles químicos, físicos, biológicos e ecológicos implicados, por exemplo, nos impactos socioambientais causados pela extração ilegal de areia e em larga escala [...] Compreender os procedimentos, como gerar uma evidência científica, como pode tomar uma decisão responsável frente a tais situações [...] Reconhecer os valores pessoais e sociais envolvidos nas questões sociocientíficas e analisa-los ética e politicamente (Ratcliffe \& Grace, 2003 apud Martínez, 2014, p. 86 - tradução nossa).

Segundo Martínez (2014), o professor de Ciências ao trabalhar com uma QSC tem o desafio de abordar aspectos culturais em sala de aula, ilustrando sobre as diversas culturas e as variadas capacidades de entendimento intercultural. $\mathrm{O}$ autor afirma que, com o estudo das QSCs, esse educador tem a possibilidade de apresentar aspectos baseados em casos. Isso consiste em discutir as controvérsias em sala de aula com objetivos de desenvolver habilidades e posicionamento crítico dos estudantes e estimular o desenvolvimento ético e moral dos mesmos.

Porém, a formação de professores tem enfrentado desafios que, de certo modo, dificultam a abordagem das QSCs (Martínez, 2014). Esses desafios estão associados a real necessidade do professor "conhecer e aprender os diferentes aspectos científicos, filosóficos, sociológicos, políticos, ambientais e éticos que contribuam na fundamentação e orientação de sua prática de ensino" (Martínez, 2014, p.86). Daí a relevância da participação desses cidadãos em processos formativos. Dessa forma, esses profissionais terão condições de dar suporte aos estudantes diante dos aspectos da natureza da ciência acerca das QSCs, além de poder direcionar aspectos do discurso em aula, valorizando a aprendizagem a partir das interações dialógicas sobre as QSCs (MARTíNEZ, 2014).

Para além dessas características das QSCs, entende-se que é importante que elas tenham algum sentido e significado para os estudantes. $E$ isso pode ser obtido por meio de um processo que consiga identificar aspectos da realidade da comunidade em que vivem os educandos, bem como as situações-limite (Freire, 1987) em que os mesmos se encontram. Para isso, é importante compreender a relação entre a Investigação 
Temática - na obtenção de Temas Geradores - e as QSCs.

\section{Procedimentos Metodológicos}

Com o objetivo de investigar o papel da Investigação Temática na seleção de QSCs, a serem trabalhadas no contexto de sala de aula, foram utilizadas informações de um processo formativo realizado no período setembro a dezembro de 2016, com carga horária de 40 horas, com professores que atuam na Educação de Jovens e Adultos (EJA), em uma escola pública localizada no distrito de Olivença, município de Ilhéus/BA. Baseado em pressupostos de Paulo Freire, o processo formativo foi organizado em colaboração com o Grupo de Estudos sobre Abordagem Temática (Geatec), vinculado à Universidade Estadual de Santa Cruz (UESC), e os educadores da escola, seguindo a Investigação Temática para a obtenção de Temas Geradores e o seu planejamento para sala de aula. Os estudos de Almeida (2018) e Bomfim (2018) apresentam com detalhes esse processo que envolveu as seguintes etapas:

a) Aproximações iniciais com a comunidade local e escolar: apresentou-se a proposta do processo formativo para os professores da escola e estabeleceu-se uma parceria com o Geatec. Além disso, obtiveram-se informações do distrito de Olivença e região por meio de blogs, dados estatísticos do município de llhéus e do distrito de Olivença, além de conversas informais com moradores. Com essas informações, elaborou-se um dossiê sobre a comunidade de Olivença;

b) Apresentação de possíveis situações-limite para a comunidade local: neste dossiê identificaram-se possíveis situações-limite do distrito de Olivença, como: compreensão acrítica e limitada sobre aspectos que envolvem a extração de areia e seus impactos para o meio ambiente; posicionamento acrítico e acomodado com relação à violência, infraestrutura, bem como a falta do sentimento de pertencimento dos moradores ao distrito de Olivença e região. Essas informações foram organizadas em um portfólio que foi apresentado para a comunidade e integrantes do Poder Público, do município de Ilhéus, com o intuito de obter entendimento, especificamente, acerca das possíveis situações-limite.

c) Legitimação da hipótese: as situações-limite identificadas foram legitimadas pelos professores e alunos da escola, moradores do distrito de Olivença e integrantes do Poder Público do município de Ilhéus e configuraram o Tema Gerador "Olivença: eu vivo em um paraíso esquecido";

d) Organização da programação Curricular: para a compreensão do Tema Gerador foram selecionados conhecimentos, conteúdos, conceitos científicos e ações 
que foram sistematizadas em uma Rede Temática (Silva, 2004) e num um Ciclo Temático (Milli, Almeida \& Gehlen, 2018). Essa organização auxiliou na elaboração do Plano de Ensino com as seguintes unidades: "Identidade histórica de Olivença", "Impactos Socioambientais" e "Infraestrutura e Economia", contemplando conhecimentos da área de História, Geografia, Literatura, Matemática, Física, Química e Biologia.

Para compreender o papel da Investigação Temática no contexto de QSC, especialmente, do Levantamento Preliminar, o presente estudo foi organizado nas seguintes etapas:

1) análise das relações entre as etapas do Levantamento Preliminar (Milli, Solino \& Gehlen, 2018) e algumas características das QSCs explicitadas no livro "Formação de professores e questões sociocientíficas: experiências e desafios na interface universidade-escola" (Martinéz et al., 2015), organizado por um grupo de pesquisadores da Colômbia. A análise teve como referência a primeira etapa do processo de Investigação Temática: Aproximações iniciais com a comunidade local e escolar, em que se realiza um dossiê da comunidade investigada. As etapas do Levantamento Preliminar foram sistematizadas por Milli, Solino e Gehlen (2008), com base nas relações entre a Investigação Temática e a Análise Textual Discursiva (Moraes \& Galiazzi, 2011), e consistem em: i) delimitação do corpus vivo, ii) cisão da realidade; iii) Relações entre as problemáticas sociais; iv) Emergência das possíveis situações-limite. As informações foram obtidas por meio de conversas informais com moradores do distrito de Olivença e em blogs e jornais regionais e, por meio da Análise Textual Discursiva (Moraes \& Galiazzi, 2011), organizou-se a categoria a priori: O papel do Levantamento Preliminar na seleção de QSCs. Para garantir a privacidade dos moradores utilizou-se o sistema alfanumérico: M1, $\mathrm{M} 2, . . . \mathrm{Mn}$ (moradores).

2) análise da temática "O Areial em Olivença/BA" relacionada à extração de areia no distrito de Olivença, como exemplo de uma QSC e a possibilidade de ser trabalhada em sala de aula. Esta análise foi realizada tendo como referência as características das QSCs, estabelecidas por Martínez (2014).

\section{O papel do Levantamento Preliminar na seleção de QSCs}

O processo de Investigação Temática foi desenvolvido por Freire (1987) e sistematizado por Delizoicov (1982) para contextos formais de ensino, sendo 
composto por cinco etapas: 1) Levantamento Preliminar: aproximação e obtenção de informações sobre a comunidade; 2) Análise das situações e escolha das codificações: seleção de elementos que expressem as contradições sociais identificadas na comunidade; 3) Diálogos descodificadores: problematização dos elementos obtidos na etapa anterior com o intuito de legitimar o Tema Gerador; 4) Redução Temática: seleção de conteúdos e conceitos científicos que possam contribuir na superação das contradições sociais e planejamento das atividades de sala de aula; 5) Trabalho em sala de aula: as atividades didático-pedagógicas planejadas são desenvolvidas em sala de aula.

Esse processo de Investigação Temática é utilizado em diversas pesquisas na área de ensino de ciências no contexto brasileiro (Delizoicov, 1982, 2008; Silva, 2004; Stuani, 2010; Lambach, 2013; Sousa et al., 2014; Magalhães et al., 2016; Mendonça, 2016; Centa \& Muenchen, 2018), assim como tem sido foco de adaptações, a exemplo de Silva (2004) que além de ampliar teórico-metodologicamente a quarta etapa - Redução Temática, organiza a investigação em Momentos. Outro exemplo é o estudo de Sousa et al. (2014) que, ao estabelecer relações entre as etapas da Investigação Temática sistematizadas por Delizoicov $(1982 ; 1991)$ e os Momentos propostos por Silva (2004), organiza o processo de investigação no contexto da formação de professores seguindo as etapas: a) aproximação inicial com a comunidade local e escolar; b) apresentação de possíveis situações-limite para a comunidade local; c) legitimação da hipótese e d) organização curricular.

Apesar de alguns estudos realizarem aprofundamentos teórico-metodológicos acerca da Investigação Temática (Silva, 2004; Sousa et al., 2014) sempre permanece a essência de todas as etapas da investigação, a exemplo do Levantamento Preliminar (Freire, 1987). Esse levantamento consiste na obtenção de informações sobre a realidade local em que vivem os estudantes, a ser realizada pela equipe de educadores, utilizando diversas atividades oriundas de fontes primárias a exemplo de visitas, conversas com moradores, consulta aos movimentos sociais organizados na região. Além disso, há necessidade de realizar a busca de fontes secundárias, como textos e dados estatísticos. Em suma, essa etapa caracteriza o levantamento das condições da comunidade em que se realiza a "primeira aproximação" com os sujeitos envolvidos, e que juntamente com os dados, informações e impressões registradas configuram um dossiê (Delizoicov, 1991).

Essas atividades propostas no Levantamento Preliminar, em primeira análise, apresentam semelhanças ao que é apresentado no livro "Formação de professores e questões sociocientíficas: experiências e desafios na interface universidadeescola", organizado por Martinéz et al. (2015), em que diversos autores relatam suas experiências e reflexões sobre a utilização das QSCs.

Em diversos capítulos deste livro, como os apresentados por Ríos et al. (2015), Benítez, 
Morales e Mora (2015), Hernández e Pérez (2015) Pérez e Lozano (2015) e Castañeda et al. (2015), evidencia-se uma proposta de sala de aula e do planejamento das aulas, para a sua implementação no ensino de Ciência. Além disso, a maioria dos autores realizam um diágnóstico para a identificação de questões relacionadas às necessidades e às controvérsias vividas pela comunidade na qual a pesquisa foi realizada, seja no contexto de bairro (local) ou em um contexto mais geral. Os pesquisadores explicam a função do diagnóstico em seus trabalhos, como ilustram os trechos:

Este diagnóstico permitiu que os alunos analisassem os problemas atuais que os afetam (locais /globais), que os interessam, relacionados a um, com um problema ambiental. (Pérez \& Lozano, 2015, p. 138 - tradução nossa)

Aplicação de um questionário diagnóstico. Cujo objetivo era investigar as concepções dos alunos sobre a qualidade da água que abastece seu município e quais as implicações de se ter uma água supostamente imprópria para consumo, isto em um questionário aberto com nove questões. (Nunes \& Dantas, 2015, p.291- tradução nossa)

Apesar de Pérez e Lozano (2015) e Nunes e Dantas (2015) explicitarem a realização de um diagnóstico para obter informações sobre a realidade em que vivem os sujeitos, tendo como objetivo resgatar elementos que possam contribuir para a delimitação da QSC, observou-se que eles não explicitam critérios para a realização desta etapa. Outro aspecto a destacar é que a QSC é uma proposta voltada para a questão científica e a partir dela discutem-se questões sociais, culturais e políticas. Porém, é possível notar que o caminho para se obter uma QSC nem sempre é o mesmo, como mostram os trechos a seguir:

[...] construiu um instrumento de abordagem, que se materializou em duas pesquisas, de modo que a questão sociocientífica surgiria das mesmas necessidades da população estudantil. Em outras palavras, considerou-se necessário reconhecer o conhecimento socialmente significativo, no qual as necessidades do mesmo contexto contribuíram na escolha de conteúdos, e desta forma os alunos poderiam ser reconhecidos como sujeitos do conhecimento dentro do mesmo processo de ensino-aprendizagem. (Ríos et al., 2015, p.45 - tradução nossa)

A equipe de professores concordou em escolher a água como eixo transversal de todo o exercício pedagógico desenvolvido com os alunos. A partir da definição da água como eixo transversal do trabalho curricular dentro da área, algumas das relações possíveis são definidas. [....]. A ideia é que cada um dos professores da área [...] possa projetar seu plano de estudos e ajustar o currículo ao eixo [...] e, portanto, às relações propostas, que estão listadas abaixo: comunidade-agua, multinacionais - água, cultura - água, água - vida e mineração - água; Com relação a esses relacionamentos, as QSCs foram estabelecidos para os ciclos do ensino básico ou secundário. (Benítez, Morales \& Mora, 2015, p.73 - tradução nossa) 
Conforme os trechos acima, é possível notar que Ríos et al. (2015) elegeram a QSC a partir das necessidades dos estudantes. Tal aspecto reforça a ideia de que a primeira etapa da Investigação Temática (Freire, 1987), sistematizada por Milli, Solino e Gehlen (2018), pode contribuir para obtenção de uma QSC, pois remete a uma problemática local que pode ter reflexos globais, tendo como ponto de partida questões sociais, culturais e políticas dos sujeitos envolvidos no processo. Além disso, conforme proposto por Milli, Solino e Gehlen (2018), são para e, a partir dessas características reais dos sujeitos, que se pode selecionar as questões científicas, tomando um caminho inverso do que se observa no estudo de Benítez, Morales e Mora (2015), que tem como ponto de partida uma QSC para em seguida situá-la no contexto social.

Para compreender o papel das etapas do Levantamento Preliminar (Milli, Solino \& Gehlen, 2018) na seleção de QSCs, buscou-se elementos na primeira etapa desenvolvida no processo formativo de professores do distrito de Olivença, que compreendeu: Aproximações iniciais com a comunidade local e escolar tendo como parâmetro os aspectos definidos por Milli, Solino e Gehlen (2018), quais sejam:

Delimitação do corpus vivo: consiste em um conjunto de informações sobre possíveis problemas vivenciados pela comunidade (Milli, Solino \& Gehlen, 2018).

No contexto do processo formativo de professores realizado na escola do distrito de Olivença, buscou-se conhecer a dinâmica da escola e comunidade e estabelecer o primeiro contato com a direção da escola. Após esse primeiro contato com os professores, investigou-se a realidade local do distrito, por meio dos principais blogs, sites e jornais da município de Ilhéus e região, bem como em teses e dissertações desenvolvidas no Programa Regional de Pós-graduação em Desenvolvimento e Meio Ambiente (PRODEMA), vinculado à UESC, no período de janeiro de 2015 até agosto de 2016. Além disso, realizaram-se visitas a alguns moradores do distrito e conversas informais com estes, com o objetivo de obter a visão dos mesmos sobre a realidade em que vivem.

Segundo Ratcliffe (2009), a QSC é uma situação problemática que afeta a comunidade, o que faz com que a etapa da delimitação do corpus seja relevante para a obtenção de uma QSC uma vez que a mesma consiste em um conjunto de informações vivenciados pela comunidade, ou seja, problemas que afetam a comunidade. Além disso, Ratcliffe (2009) aponta como uma das principais características das QSCs o fato de elas serem divulgadas em diversos meios de comunicação e propiciarem a diversidade de opiniões numa comunidade, e podem ser do tipo axiológica, político, econômica, sociais e culturais. Entende-se, então, que essa gama de informações, obtidas por meio do Levantamento Preliminar, pode possibilitar a identificação de diversas controvérsias de temas distintos.

Cisão da realidade: neste momento o pesquisador necessita realizar uma análise sistemática das informações, com o objetivo de identificar as principais situações problemáticas da comunidade. Essa identificação, na visão de Milli, Solino e Gehlen 
(2018), é realizada por meio do critério de saturação, em que se selecionam informações de mesma ordem, ou seja, informações que se apresentam de forma repetitivas.

As informações obtidas por meio de blogs configuram-se como fontes secundárias (Freire, 1987) e auxiliaram no delineamento dos principais aspectos a serem investigados no distrito de Olivença. Por meio das reportagens e utilizando-se do critério de saturação, alguns problemas se apresentaram de forma recorrente, como é possível observar na Figura 1 que retrata a questão da falta de transporte, animais soltos na rodovia e ruas esburacadas.

Figura 1: Reportagens Blog do Gusmão

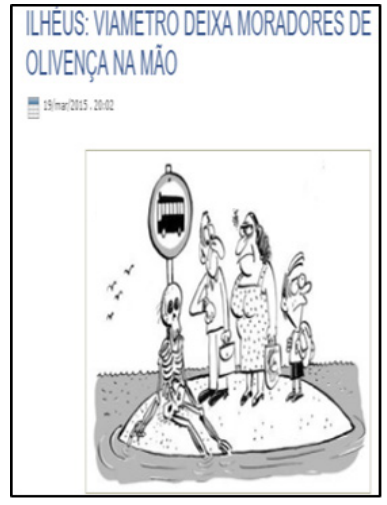

A

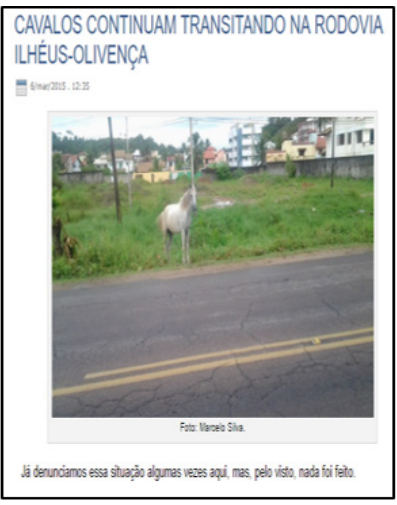

B

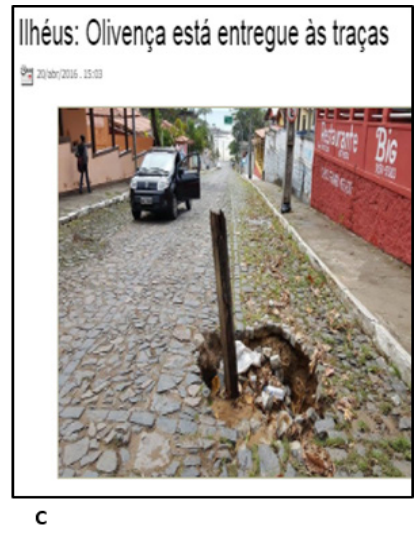

Fonte: http://www.blogdogusmao.com.br

Outras questões presentes na mídia dizem respeito à denúncia dos indígenas, que vivem numa reserva em Olivença, sobre os problemas da extração de areia, como pode ser observado na Figura 2.

Figura 2: Reportagens Blog do Gusmão 

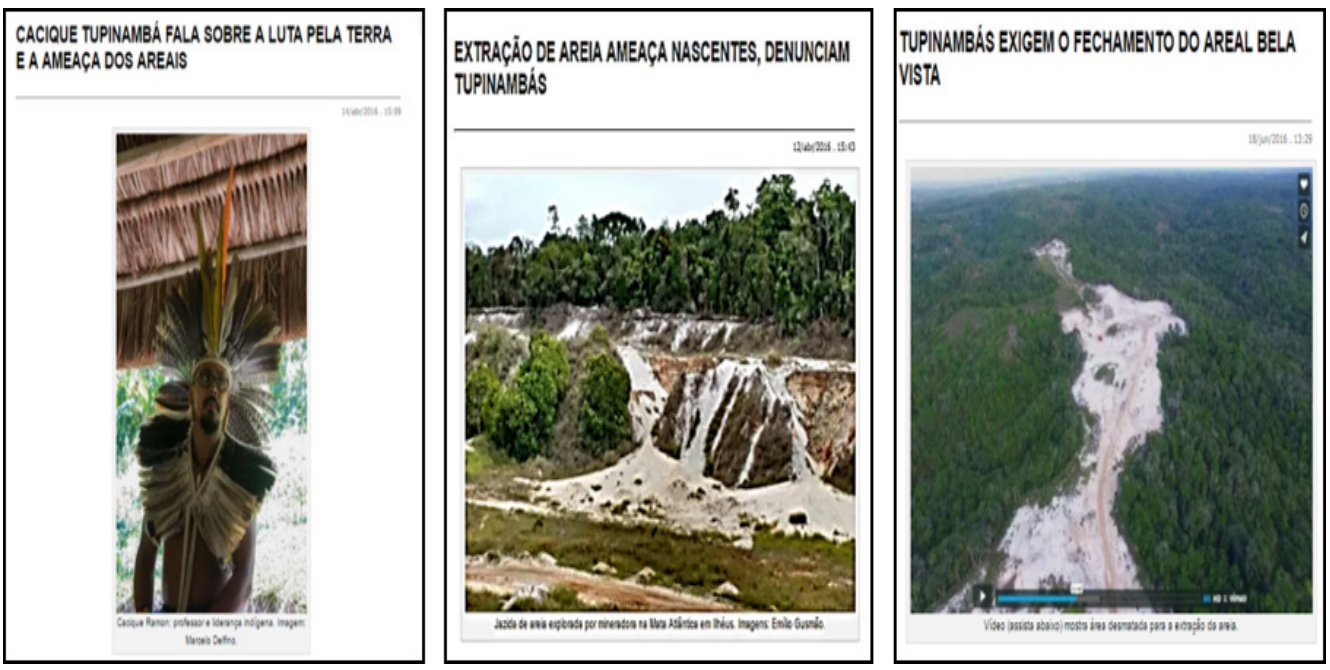

Fonte: http://www.blogdogusmao.com.br

Além das informações presentes em blogs e sites regionais, realizou-se uma busca por pesquisas no PRODEMA e localizou-se a tese de doutorado de Rocha (2014), intitulada "Bora vê quem pode mais": Uma etnografia sobre o fazer política entre os Tupinambás de Olivença (Ilhéus-BA). Dentre os apontamentos, a autora ressaltou os crimes ambientais realizados nas terras indígenas, dentre eles a extração de areia:

Um dos principais crimes ambientais cometidos por não indígenas dentro da terra indígena é extração de areia para comércio no setor da construção civil. Ainda que uma prática ilegal, diversas áreas dentro da terra indígena estão sofrendo ameaça direta dos extratores, tanto na região da costa, quanto em direção ao interior da área. Enquanto estive em campo, observei com freqüência os inúmeros caminhões carregados de areia que se deslocavam, principalmente na porção litorânea, por entre as precárias estradas de terra batida (Rocha, 2014, p.51).

Por meio da pesquisa etnográfica, a autora identificou problemas ambientais nas terras indígenas causados principalmente pela extração de areia. Além disso, por se tratar de uma atividade ilegal e os índios buscarem solução para tal, a extração de areia também tem promovido atos de violência, pois ao apresentarem-se contra o areial, os índios são ameaçados de morte pelos extratores. 


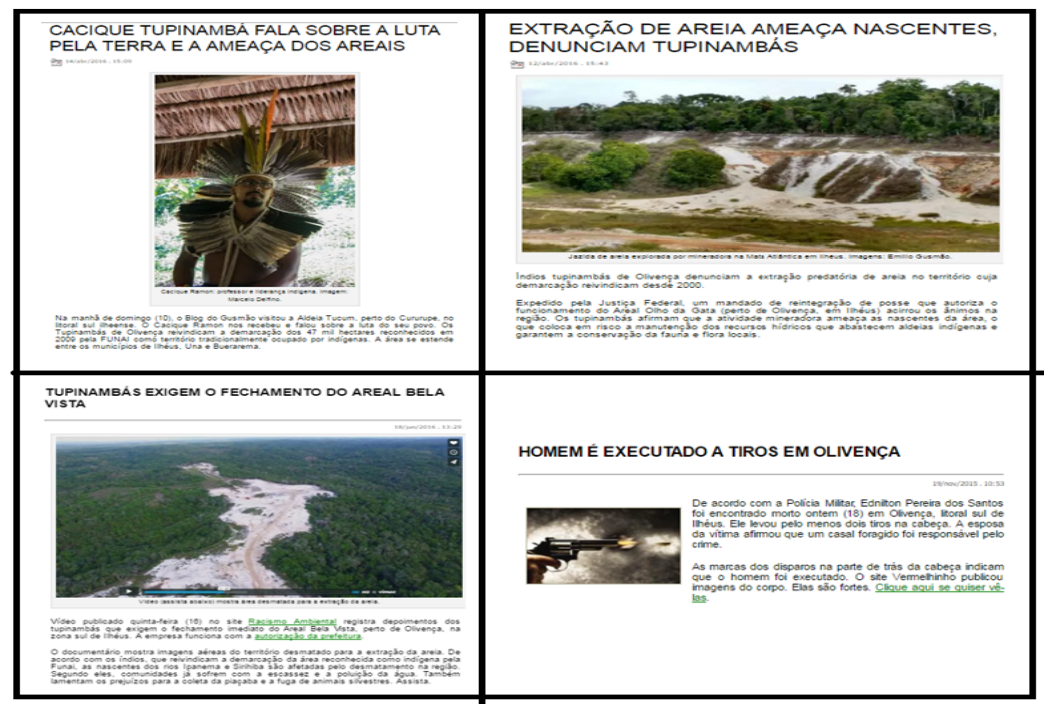

As informações dos blogs e jornais não explicitam de forma crítica essa problemática da extração ilegal de areia no distrito de Olivença, conforme constata Rocha (2014), o que justifica a necessidade de se obter informações para além da mídia. Outras fontes de informações também foram consultadas nesta etapa do levantamento de informações primárias, em que se obtiveram dados estatísticos sobre a violência, acidentes de trânsito e afogamentos na praia.

Ressalta-se que para a obtenção de uma QSC, além de identificar as principais situações problemáticas da comunidade como proposto por Milli, Solino e Gehlen (2018), é importante que o envolvidos no processo, em meio a busca por situações problemáticas, realizem esta etapa separando todos os itens que possuam alguma informação incompleta, principalmente uma evidência científica, uma vez que para Martínez (2014), as QSCs devem, entre outras características, apresentar uma lacuna, que possa ser fundamentada por meio dos conceitos científicos.

Relações entre as problemáticas sociais: nesta etapa busca-se estabelecer relações entre as informações (primárias e secundárias) obtidas da comunidade. Para isso, é realizado o agrupamento dessas informações, buscando pontos de convergência entre problemáticas que foram destacadas no momento anterior (Milli, Solino \& Gehlen, 2018). No processo formativo de professores realizado na escola localizada em Olivença, após a obtenção das informações secundárias (blog, jornais, PRODEMA, dados estatísticos), realizou-se o primeiro contato com a comunidade, fotografando, videogravando o cotidiano e os problemas do distrito. Também foram realizadas conversas informais com os moradores, com objetivo de reconhecer a comunidade e as concepções dos moradores frente à realidade do distrito. Silva (2004) afirma que 
esse contato com a comunidade permite obter falas que revelam as necessidades e os problemas que assolam esses sujeitos, bem como as possíveis soluções almejadas pelos mesmos. Quando questionados sobre os problemas existentes, alguns moradores apresentaram suas visões sobre diversos aspectos que foram agrupados em: Violência, Infraestrutura (transporte, educação e saúde) e Meio Ambiente. As falas de M2, M9 e M7, exemplificam algumas compreensões que envolvem o Meio Ambiente.

Esse rio a gente lavava até roupa [...]. Era minha filha, bebia, tomava banho, porque a água é medicinal, a de lá de cima. Ela tem iodo, ferro e magnésio [...] mas, chega aqui já topa esgoto, aí pronto. Aí polui (M2).

As praias não têm limpeza adequada. Não fazem, a limpeza é feita pelos próprios moradores. Então no dia da limpeza da praia, aí um grupo do surf que eu também faço parte que é: "Na onda da leitura" a associação de surf de Olivença e a gente que faz, cata, pega todo mundo divide em grupo, aí cada grupo fica responsável por uma praia (M9).

O dono do areal automaticamente ele dá umas ajudas, participa com a comunidade (pausa). Isto não é válido pelo consumo, pelo gasto, por toda uma história que vem por trás, porque é milhões e esses milhões são replantados? São transformados? São reaproveitados? Existe um projeto específico para um reflorestamento para cuidar da margem do rio? Eu desconheço (M9).

Não existe fiscalização nenhuma nem do lado do areal nem do lado do transporte da areia (M7).

O areal Toca do índio praticamente secou o rio ali, está acabando ali o mangue. Estraga o asfalto, destrói a natureza, destrói a fauna a flora, todo o meio, todo ecossistema, destrói as pistas (M7).

Essas falas, em síntese, apresentam a compreensão da comunidade do distrito de Olivença acerca de alguns problemas relacionados à poluição das praias e rios e, em especial, quanto à questão da extração de areia. É possível, por meio destas falas, localizar interpretações que também vão muito além daquilo que é divulgado pela mídia e dados estatísticos, a exemplo da relação do dono de um areial com a comunidade, conforme apresenta M9 e M1 explica: "sempre o dono do areal, assim na Puxada do Mastro, ele que está trazendo as camisas da festa. Patrocina e colabora com a alimentação para o povo, feijoada essas coisas ele sempre colabora".

Sabendo-se que uma QSC necessita abranger a formação de opiniões e a realização de escolhas nos níveis pessoal e social (Ratcliffe, 2009), é interessante que o pesquisador, com base nas informações já selecionadas na etapa da Cisão da realidade, procure elementos que se mostrem contraditórios quando analisados os diferentes dados para, em seguida, agrupá-los em possíveis temas que poderão ser trabalhados em diferentes 
momentos durante um ano letivo. Um exemplo disso, diante do problema do areial, seria o fato de a informação que está presente nos blogs, nem sempre ser a mesma que aparece no discurso dos moradores e/ou dos representantes do Poder Público.

Emergência das possíveis situações-limite: resulta de uma análise crítica e conjunta acerca dos grupos de informações da comunidade, identificados na etapa anterior. Assim, identificam-se as percepções dos sujeitos sobre as situações problemáticas que se manifestam nos pontos de convergência dos grupos de informações. Esse esforço permite uma compreensão mais próxima das situações-limite características da comunidade em estudo (Milli, Solino \& Gehlen, 2018). Essas situações-limite são entendidas por Freire (1987) como limite na forma que o sujeito explica sua realidade, bem como as situações contraditórias vivenciadas pelo mesmo. Indicativos dessas situações foram identificadas nas falas de moradores do distrito de Olivença, a exemplo do que colocam M4, M1, M5, M7 e M2.

Aqui é um lugar tranquilo, como o pessoal aqui fala, que aqui é um pedacinho do céu (M4).

Olivença hoje tá o melhor lugar para você morar, sabe por quê? Vai chegar uma hora que você não vai querer morar em Itabuna, não vai querer morar em Ilhéus, vai querer um sossego, aqui é um lugar para você falar assim eu vou descansar e vou viver. O índice de poluição aqui é zero, zero, zero. (M1)

[o areal] [...] não deixa de destruir, mas tá legal, eles lá dá como legal, quem sou eu pra [pausa] de que é ilegal [risos]. (M5).

[...] a construção civil não pode parar essas grandes construções que estão aí precisam de areia. (M7)

Segurança aqui... eu acho que tá legal, porque antes tinha umas violenciazinha assim né?! Mas tem muito tempo já, agora tá tranquilo, que tem um módulo ali né?! (M2).

Na compreensão dos moradores M1, M2 e M4 Olivença é um bom lugar para se morar, isento de poluição e considerada um paraíso. Contudo, as falas desses moradores não estão em consonância com os dados obtidos pelas fontes secundárias, que apresentam casos de violências e sérios problemas ambientais, vinculados principalmente com a atividade extrativista de areia das terras indígenas ${ }^{1}$. Com relação à extração de areia, M5 afirma que há destruição, no entanto apresenta uma postura acomodada por entender que os especialistas, vinculados ao órgão público, autorizam essa atividade extrativista. Já M7 defende os areiais do distrito, pois as grandes construções na região não podem parar. A partir dessas conversas informais com os moradores é possível

1 Segundo Rocha (2014), um dos principais crimes ambientais que ocorre no território indígena é a extração de areia destinada para a construção civil. Embora seja ilegal, diversos índios que se opõe a esse crime estão sofrendo ameaças dos extratores e empresários do ramo. 
identificar as possíveis controvérsias desta comunidade, uma vez que os sujeitos apresentam opiniões divergentes sobre uma mesma problemática.

Em síntese, essa etapa permitiu aos investigadores obterem as impressões que os sujeitos apresentam sobre a realidade em que estão inseridos, todavia, nem sempre essa visão expõe/denúncia os problemas da realidade. M1, M2, M4 e M5 expressam uma compreensão limitada da realidade e falta de percepção crítica, pois conforme apresentado nas informações das fontes secundárias, existem diversos problemas em Olivença. As falas da comunidade podem indicar as controvérsias vivenciadas pela comunidade, assim como são fundamentais para o planejamento de atividades didático-pedagógicas, para que os educandos possam compreendê-las e superá-las.

Para melhor compreensão de como as etapas do Levantamento Preliminar propiciaram a identificação de uma QSC, apresenta-se no tópico seguinte um exemplo de uma situação problemática do distrito de Olivença, a qual foi delimitada segundo as características de uma QSC, baseada em Martínez (2014).

\section{O areial como exemplo de uma QSC}

Apesar das etapas do Levantamento Preliminar serem originalmente propostas por Milli, Solino e Gehlen (2018) para a obtenção de situações-limites, ainda não é possível estabelecer uma relação direta das situações-limite com as QSCs. Isso se justifica pelo fato de que a QSC obtida a partir da problemática da extração de areia em Olivença não foi legitimada, ou seja, ainda não realizou-se as demais etapas da Investigação Temática para poder afirmar tal aspecto.

Passou-se, então, a analisar elementos do tema Areial tendo como parâmetro as características das QSCs, descritas por Martínez (2014), conforme Quadro 1. 
Quadro 1: Características das QSCs. Fonte: Adaptação de Martínez (2014).

\begin{tabular}{|c|c|}
\hline $\begin{array}{l}\text { Características das QSCs } \\
\text { (Martinez, 2014) }\end{array}$ & $\begin{array}{l}\text { Controvérsias associadas à extração de } \\
\text { areia }\end{array}$ \\
\hline $\begin{array}{l}\text { Se baseiam na ciência, geralmente } \\
\text { em áreas que estão nas fronteiras do } \\
\text { conhecimento científico. }\end{array}$ & $\begin{array}{l}\text { - Pesquisas evidenciam que a extração de } \\
\text { areia causa impactos socioambientais; } \\
\text { - Estudos científicos sobre o impacto } \\
\text { ambiental da extração de areia e seus } \\
\text { efeitos geomorfológicos nos rios; }\end{array}$ \\
\hline $\begin{array}{l}\text { Eles geralmente são relatados pelos } \\
\text { meios de comunicação de massa, } \\
\text { destacando aspectos relacionados } \\
\text { com seus interesses. }\end{array}$ & $\begin{array}{l}\text { - Por ser um problema local, não tem } \\
\text { vinculação na mídia. Apenas algumas } \\
\text { reportagens e vídeos < http://www. } \\
\text { blogdogusmao.com.br> }\end{array}$ \\
\hline Enfrentam problemas locais e globais. & $\begin{array}{l}\text { - A extração de areia em grande escala é } \\
\text { uma problemática global; } \\
\text { - A extração de areia que envolve índios } \\
\text { nativos, suborno e medo, é local; } \\
\text { - Polêmica entre os índios e os responsáveis } \\
\text { pela extração de areia no distrito de } \\
\text { Olivença; } \\
\text { - Desmatamento; } \\
\text { - Alteração na biodiversidade; } \\
\text { - Aceleração do processo erosivo; } \\
\text { - Alteração nas propriedades físico- } \\
\text { químicas e mecânicas do solo; } \\
\text { - Deterioração de solos para sustentar a } \\
\text { construção civil. }\end{array}$ \\
\hline $\begin{array}{l}\text { Abrangem a formação de opiniões e } \\
\text { a realização de escolhas nos níveis } \\
\text { pessoal e social. }\end{array}$ & $\begin{array}{l}\text { - Opiniões a favor da extração oferta de } \\
\text { empregos para a comundade; } \\
\text { - Opiniões contra os perigos associados à } \\
\text { interferência ambiental. }\end{array}$ \\
\hline $\begin{array}{l}\text { Enfrentam informações incompletas, } \\
\text { seja evidência científica incompleta } \\
\text { ou de confronto, ou de lacunas nos } \\
\text { registros. }\end{array}$ & $\begin{array}{l}\text { - Há dúvidas sobre a necessidade da } \\
\text { utilização de areia nas construções civis, } \\
\text { por causa dos impactos que podem gerar } \\
\text { sua extração em larga escala a nível local. }\end{array}$ \\
\hline
\end{tabular}




\begin{tabular}{|c|c|}
\hline $\begin{array}{l}\text { Abrangem análise de custos e } \\
\text { benefícios em que os riscos interagem } \\
\text { com os valores. } \\
\text { Pode exigir alguma compreensão de } \\
\text { probabilidade e risco. }\end{array}$ & $\begin{array}{l}\text { - Extração de areia versus construção civil; } \\
\text { - Extração em larga escala para atender } \\
\text { à procura de areia diante da demanda } \\
\text { econômica local. }\end{array}$ \\
\hline $\begin{array}{l}\text { Podem incluir considerações sobre } \\
\text { sustentabilidade. }\end{array}$ & $\begin{array}{l}\text { - Objeções para a extração da areia porque } \\
\text { intervém no meio físico; } \\
\text { - A quem cabe a dominialidade do areial e } \\
\text { quais entidades públicas devem zelar pela } \\
\text { sua preservação para as futuras gerações? }\end{array}$ \\
\hline Abrangem valores e raciocínio ético. & $\begin{array}{l}\text { - Existem dilemas éticos em relação } \\
\text { à extração de areia para atender às } \\
\text { demandas da construção civil e do } \\
\text { crescimento econômico em vez de } \\
\text { usar outras alternativas ou técnicas de } \\
\text { manipulação desses areais; } \\
\text { - Prestação de serviços sociais a fim de } \\
\text { evitar intervenções. }\end{array}$ \\
\hline
\end{tabular}

Conforme consta no Quadro 1, o tema Areial, identificado por meio da primeira etapa da Investigação Temática apresenta características de uma QSC proposta por Martínez (2014), o que também corrobora com a utilização das etapas do Levantamento Preliminar (Milli, Solino \& Gehlen, 2018) como ferramenta metodológica para a obtenção e legitimação da QSC como uma alternativa viável.

Além disso, as características das QSCs apresentadas por Martínez (2014) contribuem para legitimar que a controvérsia do Areial configura-se como sendo uma controvérsia socioambiental, uma vez que envolve "cientistas, decisores políticos e grupos de cidadãos" (Reis, 2009, p. 10), expondo suas diferentes percepções em relação, por exemplo, ao impacto ambiental de algum empreendimento.

A organização do Quadro 1 também auxiliou na escolha do título da controvérsia que é "A extração de areia, enquanto um recurso econômico local, promovendo impactos ambientais em Olivença - Ilhéus (BA)". Analisando o Quadro e a controvérsia delimitada, elaborou-se a pergunta que norteará o planejamento didático-pedagógico, que é "A extração de minérios causam vários impactos socioambientais, no entanto no modelo de sociedade que estamos inseridos atualmente, essa atividade torna-se uma excelente alternativa para a obtenção de areia que, por exemplo, é uma das matériasprimas mais utilizada na construção civil. Quais os pontos positivos e negativos da 
extração de areia em Olivença?"

A partir dessa controvérsia delimitou-se o título da QSC como "Extração ilegal de areia: Impactos x Benefícios". Por conseguinte, iniciou-se a escolha de conhecimentos e ações envolvidos nesta QSC, que pode ser abordada em diversas áreas do conhecimento. Para tanto, utilizou-se como parâmetro para a organização dos conteúdos - que contribuirão para o entendimento e tomada de decisões dos educandos acerca da QSC - a sua articulação com o eixo transversal. De acordo com Benítez, Morales e Mora (2015), esse eixo consiste nas relações existentes entre o tema, no caso Areial, e os problemas que envolvem esse tema, a exemplo de areial-vida, areial-desmatamento, areial-rios. A partir desse fato é possível estabelecer conteúdos necessários para discutir sobre este eixo, como ilustra o Quadro 2. No caso de areial-rios, por exemplo, faz-se necessário a discussão de conteúdos relacionados com a hidrografia, para que os educandos possam compreender como acontece a formação dos rios e como a extração de areia de forma irregular pode prejudicar as nascentes.

Quadro 2 - Conteúdos disciplinaras e a QSC adaptado de Benítez, Morales e Mora (2015).

\begin{tabular}{|c|c|c|}
\hline $\begin{array}{l}\text { Conteúdo } \\
\text { disciplinar }\end{array}$ & $\begin{array}{l}\text { Articulação do conteúdo com o } \\
\text { eixo transversal }\end{array}$ & $\begin{array}{l}\text { Questão socioambiental ou } \\
\text { sociocientífica }\end{array}$ \\
\hline $\begin{array}{l}\text { Desmatamento } \\
\text { da mata ciliar }\end{array}$ & $\begin{array}{l}\text { - Preservação da vida e da } \\
\text { natureza no areial; } \\
\text { - Diminuição da área verde, } \\
\text { o rebaixamento do nível do } \\
\text { lençol freático e as relações na } \\
\text { manutenção da qualidade da } \\
\text { água. }\end{array}$ & $\begin{array}{l}\text { - Implicações na fauna e na } \\
\text { flora; } \\
\text { - Contaminação da água e } \\
\text { as relações com o consumo } \\
\text { e a saúde da população } \\
\text { indígenas; } \\
\text { - Aumento do assoreamento } \\
\text { dos rios que originam a água } \\
\text { consumida pelos indígenas. }\end{array}$ \\
\hline $\begin{array}{l}\text { Ciclos } \\
\text { biogeoquímicos }\end{array}$ & $\begin{array}{l}\text { - Queimadas para exploração da } \\
\text { área; } \\
\text { - Impactos no areial e nascente } \\
\text { dos rios. }\end{array}$ & $\begin{array}{l}\text { - Impactos socioambientais, } \\
\text { como a destruição da mata } \\
\text { nativa; } \\
\text { - A extinção de animais e } \\
\text { árvores nativas }\end{array}$ \\
\hline Hidrografia & $\begin{array}{l}\text { - Nascentes e alteração dos } \\
\text { cursos dos rios; } \\
\text { - O devastamento da Mata } \\
\text { Atlântica em benefício da } \\
\text { extração da areia. }\end{array}$ & $\begin{array}{l}\text { - A extração de areia e o } \\
\text { mau uso do solo por meio } \\
\text { da mineração ameaça } \\
\text { as nascentes da área e } \\
\text { compromete a conservação } \\
\text { da fauna e flora local; } \\
\text { - A população indígena }\end{array}$ \\
\hline
\end{tabular}




\begin{tabular}{l|l} 
Identidade & - Cultura, costumes e tradições \\
Cultural de um & da comunidade em relação à área \\
povo; Discurso & devastada e exploração da na \\
ideológico e & extração de areia; \\
alienação & - Alienação da comunidade \\
& $\begin{array}{l}\text { quanto a real situação do areal } \\
\text { em trocas de favores entre os } \\
\text { empresários e moradores. }\end{array}$
\end{tabular}

\section{Ética e Política - Perda da identidade cultural e} política da comunidade indígena;

Desvalorização dos recursos naturais em sobreposição à questão econômica e a subsistência financeira das classes desfavorecidas da localidade.
- O poder ideológico

acerca da questão política, econômica e social vivenciada pelos moradores no tocante a destruição ecológica do local sagrado (indígenas).

- O distanciamento da cultura nativa da comandada com relação aos valores éticos;

A devastação da mata atlântica e as implicações sociais, ambientais, éticas e políticas que interferem no comportamento das pessoas.

O Quadro 2 mostra que quando se trabalha com uma controvérsia, que emerge de uma realidade local, há possibilidade de se abordar conteúdos e conceitos científicos de diversas áreas do conhecimento, não só as Ciências Naturais, mas também das Ciências Humanas, discutindo questões relacionadas à ética e valores.

Além das etapas do Levantamento Preliminar (Milli, Solino \& Gehlen, 2018) apresentarem suporte para a obtenção da QSC, também possibilitam a obtenção de uma questão socialmente viva. Essas são questões que, segundo Simoneaux (2003), acarretam alguma controvérsia e polêmica na sociedade, tendo as seguintes características: suscitar debates durante a produção de saberes; insere-se no contexto social e mediático e os professores e alunos não podem deixar de discutir sobre; os professores em sua maioria não se sentem preparados para abordar tais questões.

Com base nessas características, nota-se que a controvérsia "A extração de areia, enquanto um recurso econômico local, promovendo impactos ambientais em Olivença - Ilhéus/BA " apresenta semelhanças com o que é descrito por Simoneaux (2003), tendo em vista que trata-se de uma questão que precisa ser discutida no contexto de sala de aula. Além disso, o problema da extração de areia em Olivença está presente na realidade tanto dos alunos como dos professores, acarretando uma necessidade ainda maior em discutir essa temática. Porém, ao mesmo tempo em que se reconhece a importância dessa temática, a mesma demanda alguns cuidados com relação à forma de discussão em sala de aula, pois é um tema que envolve além dos impactos ambientais, disputas de poder e por terras na comunidade, aspecto que também é apresentado por Simoneaux (2003), uma vez que os professores podem não se sentirem preparados 
para abordar uma questão deste tipo.

O tópico seguinte apresentará a estrutura da aula esquematizada visando favorecer a participação ativa dos estudantes em discussões escolares que enriqueçam seu crescimento pessoal e social, fomentando uma possível ação social responsável dos sujeitos inseridos nesse contexto de sala de aula de uma escola do distrito de Olivença.

\section{O areial em sala de aula}

Elaborou-se uma proposta de sala de aula a partir da QSC identificada no distrito de Olivença, para alunos da EJA (Eixo II), na disciplina de Ciências da Natureza. Tratase de uma sequência de aula elaborada tendo como referência elementos básicos a serem trabalhados no contexto de uma QSC, apresentados por Benítez, Morales e Mora (2015), conforme ilustra o Quadro 3:

Quadro 2 - Conteúdos disciplinaras e a QSC adaptado de Benítez, Morales e Mora (2015).

\section{Elementos básicos de uma sequência didática}

Pergunta norteadora Deve ser considerada a partir do contexto disciplinar, com o objetivo de despertar interesse no aluno, o que permitirá que outras questões inerentes aos problemas surgam.

Tema

Define-se a partir da relação da questão orientadora com os conteúdos em geral.

Conteúdos

Selecionado a partir da pergunta e do tema. O conteúdo deve fornecer os elementos teóricos e conceituais que permitam aos alunos argumentar, explicar, interpretar, assumir posições críticas diante da problemática proposta.

Abordagem

Metodológica

Bibliografia e cibernética
É orientada para problematizar os conceitos e conteúdos. Portanto, pode-se utilizar algumas abordagens que possam contribuir na discussão da QSC, como a criação de técnicas de comunicação, como o debate, a mesa redonda, o fórum, o painel, a dramatização, aplicar teste de entrada e saída (avaliação), etc.

Refere-se aos textos e páginas de Internet consultadas durante o processo. 
Com base nesses elementos, elaborou-se uma sequência baseada na QSC do Areial.

Quadro 4 - Organização da aula com base nas etapas de Benítez, Morales e Mora (2015).

Tema: Areial de Olivença/BA

Controvérsia: A extração de areia, enquanto um recurso econômico local, promovendo impactos ambientais em Olivença - Ilhéus/BA

Questão sociocientífica: Extração ilegal de areia: Impactos x Benefícios.

Pergunta Norteadora: "A extração de minérios causam vários impactos socioambientais, no entanto no modelo de sociedade que estamos inseridos atualmente, essa atividade torna-se uma excelente alternativa para a obtenção de areia, por exemplo, que é uma das matérias-primas mais utilizada na construção civil." Quais os pontos positivos e negativos da extração de areia em Olivença?

Conteúdos: Dispostos no Quadro 2

Abordagem metodológica: Debate

Bibliografia: Vídeo e reportagens sobre o areial de Olivença-BA

$1^{\circ}$ Momento Quem são os personagens dessa problemática? Qual a posição e os interesses de cada um deles? Você, como morador da comunidade, também é um personagem dessa história?

$2^{\circ}$ Momento Debate. Até que ponto a extração de areia em Olivença beneficia a comunidade em geral? De quem é a responsabilidade sobre a fiscalização da extração de areia em Olivença?

$3^{\circ}$ Momento Confecção de um blog.

a) Controvérsia, QSC e pergunta norteadora

Após a controvérsia social ser elencada durante a Aproximação Inicial com a comunidade local e escolar, no processo de formação realizado no distrito de Olivença, obtevese a seguinte QSC: "Extração ilegal de areia. Impactos da extração de areia" e após organizou-se a pergunta norteadora: "A extração de minérios causam vários impactos socioambientais, no entanto no modelo de sociedade que estamos inseridos atualmente, essa atividade torna-se uma excelente alternativa para a obtenção de areia, por exemplo, que é uma das matérias-primas mais utilizada na construção civil." Quais os pontos positivos e negativos da extração de areia em Olivença? Essa pergunta deverá orientar o docente no desenvolvimento das atividades subsequentes. 


\section{b) A abordagem metodológica e os conteúdos}

O exemplo apresentado no Quadro 4 foi desenvolvido para ser utilizado tanto em disciplinas de Ciências na Natureza como nas que envolvem a Ciências Humanas, podendo ser adaptada conforme os conteúdos da área de conhecimento. Como a abordagem metodológica é escolhida para problematizar o conceito e o conteúdo, o debate também se mostra como uma opção a ser utilizada.

\section{c) Os momentos da sequência}

$1^{\circ}$ Momento: será apresentado um documentário que retrata os principais impactos ambientais causados pela extração de areia nas terras indígenas em Olivença. Após a exposição do vídeo, o docente promoverá uma discussão inicial, por meio da questão: "Quem são os personagens dessa problemática? E qual a posição e os interesses de cada um deles? Você, como morador da comunidade, também é um personagem dessa história?" Tais perguntas têm como objetivo incencetivar os educandos a entenderem que eles também estão imersos na problemática do areial de Olivença, além de despertar neles o interesse e a curiosidade em entender tal problema.

$2^{\circ}$ Momento: será proposto um debate norteado pelas seguintes questões: Até que ponto a extração de areia em Olivença beneficia a comunidade do distrito? De quem é a responsabilidade sobre a fiscalização da extração de areia em Olivença? Nessa etapa será analisada a participação dos alunos e a argumentação apresentada pelos mesmos, com o objetivo de identificar o quanto eles se sentem pertencentes daquele problema proposto na controvérsia e discutir com eles, por meio dos conceitos científicos, a consequência que esta extração traz para a nascente do rio, por exemplo. Além disso, iniciar-se-á uma busca - por meio de um trabalho colaborativo entre professor e alunos - de possíveis soluções do problema a partir dos conceitos científicos como os descritos no Quadro 2.

$3^{\circ}$ Momento: será confeccionado um blog em que serão elencados os principais impactos socioambientais causados pela extração de areia no distrito de Olivença, evidenciando os benefícios e malefícios deste areial para a comunidade. Os alunos deverão disponibilizar neste blog alguns informativos sobre possíveis alternativas para a solução deste problema, conforme discussão apresentada no segundo momento. Por conseguinte, sugere-se que este blog seja divulgado e apresentado na escola com o intuito de conscientizar a comunidade escolar acerca das problemáticas que envolvem o areial.

É importante destacar que esses três momentos não correspondem à dinâmica dos Três Momentos Pedagógicos (3MP's) (Delizoicov, Angotti \& Pernambuco, 2002). Entretanto, em trabalhos futuros é importante investigar a relação da proposta de sequência de Benítez, Morales e Mora (2015) da abordagem de uma QSC com os 3MP's, utilizando como critério de seleção da QSC as etapas da Investigação Temática. 


\section{Considerações Finais}

Apresentou-se, neste trabalho, uma breve discussão sobre a necessidade da Educação em Ciências abarcar assuntos que envolvem fatores sociais, políticos e científicos, capazes de possibilitar ao educando reflexões e posicionamento críticos acerca de questões mais amplas, resultando numa ação social responsável. Para tanto, constatou-se que vários trabalhos dos pesquisadores Colombianos, que utilizam a abordagem das QSCs (Ríos et al., 2015; Benítez, Morales \& Mora, 2015; Hernández \& Pérez, 2015; Pérez \& Lozano, 2015 e Castañeda et al., 2015), envolvem questões relacionadas aos aspectos científicos, políticos, éticos e morais que resultam em fortes impactos globais.

No processo formativo de professores realizado no distrito de Olivença, constatou-se que a primeira etapa da Investigação Temática - Aproximações iniciais com a comunidade local e escola - apresenta elementos que contribuem significativamente para a seleção de QSCs. As etapas do Levantamento Preliminar (Milli, Solino \& Gehlen, 2018) são essenciais para a localização de possíveis situações-limite e, como se observou na análise das informações do distrito de Olivença, configuram-se como uma ferramenta para eleger uma QSC, principalmente, quando se trata de uma temática local, como foi o caso do Areial de Olivença/BA.

Com isso, amplia-se a forma de se obter informações e sistematizá-las, na fase do diagnóstico - apresentado pelo grupo de pesquisadores da Colômbia -, para identificar uma QSC (Ríos et al., 2015; Pérez \& Lozano, 2015; Nunes \& Dantas, 2015; Benítez, Morales \& Mora, 2015; Hernández \& Pérez, 2015 e Castañeda et al.,2015), uma vez que o Levantamento Preliminar contém elementos que auxiliam a seleção de QSCs, como as situações-limite. De acordo com Freire (1987), as situações-limite apresentam dimensões desafiadoras, concretas e históricas de uma dada realidade. Já para a obtenção de controvérsias sociocientíficas que compõem uma QSC, faz-se necessário que o pesquisador tenha um olhar atento para aspectos que remetam à CTSA (Martínez, 2014), possibilitando a delimitação de uma QSC. Portanto, ao utilizar - Levantamento Preliminar para a obtenção de uma QSC é importante ir além do que é proposto por Milli, Solino e Gehlen (2018) mantendo o foco, também, em questões científicas e tecnológicas.

É importante lembrar que nessa primeira etapa da Investigação Temática foram localizadas possíveis situações-limite (Milli, Solino \& Gehlen, 2018) que, ainda, necessitam ser legitimadas para que se possa afirmar se realmente são Temas Geradores. Mesmo não tendo a confirmação desses temas na primeira etapa da investigação é possível identificar controvérsias, a exemplo de uma controvérsia socioambiental (Reis, 2009) como o areial em Olivença. Então, é importante esclarecer que o tema "Areial de Olivença/BA" não é um Tema Gerador, mas sim uma QSC que foi identificada na primeira etapa da Investigação Temática e que pode vir a ser um 
Tema Gerador, desde que sejam realizadas as etapas da codificação e descodificação (Freire, 1987) da investigação.

Outro aspecto a destacar é que quando a QSC emerge de uma realidade local e de uma problemática próxima da vivência dos sujeitos da pesquisa (educandos e professores da escola) há possibilidades de se pensar em conteúdos que vão além das Ciências Naturais. E, com isso, possibilitar discussões em sala de aula sobre questões relacionadas à ética e valores presentes nas Ciências Naturais, numa dimensão axiológica e ontológica, também fundamentais para o desenvolvimento crítico dos sujeitos.

\section{Referências}

Almeida, E. S. (2018). A Investigação Temática na perspectiva da articulação FreireCTS. (Dissertação de Mestrado em Educação em Ciências). Universidade Estadual de Santa Cruz, Ilhéus, BA.

Auler, D., \& Delizoicov, D. (2015). Investigação de temas CTS no contexto do pensamento latino-americano. Linhas Críticas, Brasília, 21(45), 275-296.

Bazzo, W. A. (1998) Ciência, Tecnologia e Sociedade: e o contexto da educação tecnológica. Florianópolis: Editora da UFSC.

Benítez, M. S. E., Morales, M., \& Mora, M. R. (2015). Una experiencia educativa sobre la problemática ambiental del agua de los cerros orientales: reflexiones y aportes desde la escuela. En Leonardo, F. M. P., Diana, L. P. L., \& Isabel, G. B. (Eds.), Experiencias y desafíos en la interfaz universidad escuela (pp 61-80). Bogotá: Universidad Pedagógica Nacional.

Bonfim, M.G. (2018). O Potencial Gnosiológico da Abordagem Temática: um olhar sobre o processo formativo de professores da EJA. (Dissertação de Mestrado em Educação em Ciências). Universidade Estadual de Santa Cruz, Ilhéus, BA.

Castañeda, P. N. Z., Fernández, M. R. R., Ortega, O. A., Ardila, A. D. F., \& Nausa, B. N. (2015). La enseñanza de las ciencias a través de cuestiones sociocientícas: una experiencia con profesores en formación inicial. In F. M. P. Leonardo, L. P. L. Diana $\&$ G. B. Isabel (eds.), Experiencias y desafíos en la interfaz universidad escuela ( $p p$ 141-168). Bogotá: Universidad Pedagógica Nacional. 
Centa, F.G., \& Muenchen, C. (2018). O trabalho coletivo e interdisciplinar em uma reorientação curricular na perspectiva da Abordagem Temática Freireana. Revista Eletrónica de Enseñanza de las Ciencias. 17(1), 68-93.

Delizoicov, D. (1982). Concepção Problematizadora do Ensino de Ciências na Educação Formal (Dissertação de mestrado em Educação). Pontifícia Universidade Católica, São Paulo.

Delizoicov. D. (1991). Conhecimento, tensões e transições. (Tese de Doutorado em Educação). Universidade de São Paulo, São Paulo.

Delizoicov, D., Angotti, J. A., \& Pernambuco, M. M. Ensino de Ciências: fundamentose métodos. São Paulo: Cortez, 2002.

Delizoicov, D. (2008). La Educación en Ciencias y la Perspectiva de Paulo Freire. Alexandria - Revista de Educação em Ciência e Tecnologia,1(2), 37-62.

Fazenda, I. (1993). A Interdisciplinaridade: um projeto em parceria. São Paulo: Loyola. Freire, P. (1987). Pedagogia do oprimido. 17 ed. Rio de Janeiro: Paz e Terra.

Freire, P. (1996). Pedagogia da autonomia: saberes necessários à prática educativa. São Paulo: Paz e Terra.

Hernández, B. R., \& Pérez, L. M. (2015). ¿Las sustancias psicoactivas se debaten o combaten en la escuela? "Controversia por la legalidad/ilegalidad": una experiencia de formación de docentes en la interfaz universidad-escuela. En Leonardo, F. M. P., Diana, L. P. L., \& Isabel, G. B. (Eds.), Experiencias y desafíos en la interfaz universidad escuela (pp 81-108). Bogotá: Universidad Pedagógica Nacional.

Lambach, M. (2013). Formação Permanente de Professores de Química da EJA na Perspectiva Dialógico-Problematizadora Freireana. (Tese de Doutorado em Educação Científica e Tecnológica). Universidade Federal de Santa Catarina, Florianópolis.

Magalhães, R.S., Solino, A. P., Sousa, P. S., Fonseca, K. N., Novais, E. S., \& Gehlen, S. T. (2016). Situações-Limite na formação de professores de ciências na perspectiva. Investigação em Ensino de Ciências. 21 (3), 127-151.

Martínez, L. F. P., \& Carvalho, W.L.P. (2012). Contribuições e dificuldades da abordagem de questões sociocientíficas na prática de professores de ciências. Educação e Pesquisa, São Paulo, v. 38 (03), 727-741. 
Martínez, L. F. P., Carvalho, W.L.P., Lopes, N.C., Carnio, M.P., \& VARGAS, N.J.B. (2011). A Abordagem de questões sociocientíficas no Ensino de Ciências: contribuições à pesquisa da área. In: VIII Encontro Nacional de Pesquisa em Educação em Ciências. Curitiba. Disponível em: < http://www.nutes.ufrj.br/abrapec/viiienpec/resumos/ R1606-1.pdf >. Acesso em 10/01/2018.

Martínez, L.F.P. (2012). Questões sociocientíficas na prática docente: Ideologia, autonomia e formação de professores [online]. São Paulo: Editora UNESP, 360 p. ISBN 978-85-3930-354-0.

Martínez, L., \& Lozano, D. L. P. (2013). La Emergencia de las Cuestiones Sociocientíficas en el enfoque CTSA. Góndola enseñanza y aprendizaje de las ciencias. Vol. 8 (1), 23-35.

Martínez, L. (2014). Cuestiones sociocientíficas en la Formación de profesores de Ciencias: aportes y desafíos. Tecné, Episteme y Didaxis. (36), 77-94.

Mendonça, A.R. (2016). A aposta da reorientação curricular via Tema Gerador no Projeto Parnamirim Interdisciplinar. (Dissertação de Mestrado em Educação). Universidade Federal do Rio Grande do Norte, Natal, RN.

Milli, J. C.L., Solino, A. P., \& Gehlen, S. T. (2018) A Análise Textual Discursiva na pesquisa do Tema do Gerador: onde e como começar? Investigações em Ensino de Ciências, 23(1), 200-229.

Milli, J. C.L., Almeida, E. S., \& Gehlen, S. T. (2018) A Rede Temática e o Ciclo Temático na Busca pela Cultura de Participação na Educação CTS Alexandria - Revista de Educaçãoem Ciência e Tecnologia, 11(1), 71-100.

Moraes, R., \& Galiazzi, M. C. (2011) Análise Textual Discursiva. ljuí: UNIJUÍ.

Nunes, A. O., \& Dantas, J. M. (2015). Mestrados Profissionais em Ensino: posibilidades de formação continuada para profesores de química brasileiros na interface Universidade-Escola. In F. M. P. Leonardo, L. P. L. Diana, \& G. B. Isabel (eds.), Experiencias y desafíos en la interfaz universidad escuela (284-306). Bogotá: Universidad Pedagógica Nacional.

Pérez, D. C. C., \& Lozano, D. L. P. (2015). Diseño curricular a partir de cuestiones sociocientícas. In Leonardo, F. M. P., Diana, L. P. L., \& Isabel, G. B. (eds.), Experiencias y desafíos en la interfaz universidad escuela (pp 109-140). Bogotá: Universidad Pedagógica Nacional. 
Pinheiro, N. A. M., Silveira, R. M. C. F., \& Bazzo, W. A. (2007). Ciência, tecnologia e sociedade: a relevância do enfoque CTS para contexto do ensino médio. Ciência \& Educação, 13(1), 71-84. Disponível em: <http://www.scielo.br/pdf/ciedu/v13n1/ v13n1a05.pdf >. Acesso em 09/01/2018.

Ratcliffe, M., \& Grace, M. (2003). Science education for citizenship: teaching socioscientific issues. Maidenhead: Open University Press.

Ratcliffe, M. (2009). Human Rights and Citizenship Education. Eleventh Conference of the Children's Identity and Citizenship in Europe Academic Network.

Reis, P. R. (2009). Ciência e controvérsia. REU, 35(2), 9-15.

Ríos, L. C. A., Bautista, D. M. P., Sánchez, K. A. G., Osorio, N. R., Castañeda, C. A. R.; Obando, A. A., Rincón, L. E.; Villamil, D. W., Torres, M. R. H., Garzón, C. E. G., \& Acosta, C. G. G. (2015). Articulación de cuestiones sociocientícas al currículo escolar: aportes construidos a partir de la investigación-acción. In Leonardo, F. M. P., Diana, L. P. L., \& Isabel, G. B. (eds.), Experiencias y desafíos en la interfaz universidad escuela (35-60). Bogotá: Universidad Pedagógica Nacional.

Rocha, C.C. (2014). "Bora vêquem pode mais": Uma etnografia sobre ofazer política entre os Tupinambá de Olivença (Ilhéus, Bahia) (Tese de Doutoramento em Antropologia Social), UFSC, Florianópolis.

Santos, W. L. P. (2007). Educação científica na perspectiva de letramento como prática social: funções, princípios e desafios. Revista Brasileira de Educação, 12, 474492.

Silva, A. F. G. (2004). A construção do currículo na perspectiva popular crítica: das falas significativas às práticas contextualizadas. (Tese de Doutorado em Educação e Currículo). Pontifíca Universidade Católica de São Paulo, São Paulo.

Sousa, P. S., \& Gehlen, S. T. (2017). Questões Sociocientíficas no Ensino de Ciências: algumas características das pesquisas brasileiras. Revista Ensaio. Belo Horizonte. 19, e2569. Disponível em: < http://www.scielo.br/pdf/epec/v19/1983-2117-epec19-e2569.pdf>. Acesso em: 03 de jan. 2018.

Sousa, P. S., Bastos, A. P. S., Figueiredo, P. S., \& Gehlen, S. T. (2014). Investigação Temática no Contexto do Ensino de Ciências: Relações entre a Abordagem Temática Freireana e a Práxis Curricular via Tema Gerador. Alexandria - Revista de Educação em Ciência e Tecnologia, 7(2), 155-177. 
Stuani, G. M. (2010). A Construção curricular popular crítica no ensino de Ciências Naturais e suas implicações na prática docente. (Dissertação de Mestrado em Educação Científica e Tecnológica). Universidade Federal de Santa Catarina, Florianópolis, SC.

Simmoneaux, L. (2003). L'argumentation dans les débats en classe sur une technoscience controversée. ASTER, 37, 189-214.

Valéria Bonfim Santos é Graduada em Física Licenciatura Plena pela Universidade Estadual de Santa Cruz (2017), mestranda em Educação em Ciências pela Universidade Estadual de Santa Cruz. Atualmente faz parte do Grupo de Estudos sobre Abordagem Temática Freireana (GEATEC), atuando principalmente nas aproximações entre as ideias de Lev S. Vygotsky e Paulo Freire e Abordagem Temática Freireana.

Josenilda Assunção é Graduada em Física Licenciatura Plena pela Universidade Estadual de Santa Cruz (2011), mestranda em Educação em Ciências pela Universidade Estadual de Santa Cruz. Atualmente faz parte do Grupo de Estudos sobre Abordagem Temática Freireana (GEATEC), atuando principalmente nas relações entre Vasconcellos e Abordagem Temática Freireana, na elaboração de Projetos Políticos Pedagógicos de escolas.

Manuela Gomes Bomfim é Graduada em Biologia Licenciatura Plena pela Universidade Estadual de Santa Cruz (2016) e Mestre em Educação em Ciências pela Universidade Estadual de Santa Cruz (2018).

Jeruza Rocha Lima Arcanjo é Graduada em Filosofia Licenciatura Plena pela Universidade Estadual de Santa Cruz (1996), mestranda em Educação em Ciências pela Universidade Estadual de Santa Cruz.

Simoni Tormöhlen Gehlen é Graduada em Física Licenciatura Plena pela Universidade Federal de Santa Maria (2002), mestrado em Educação nas Ciências pela Universidade Regional do Noroeste do Estado do Rio Grande do Sul - UNIJUí (2006) e doutorado em Educação Científica e Tecnológica pela Universidade Federal de Santa Catarina - UFSC (2009). Atualmente é professora do curso de Licenciatura em Física da Universidade Estadual de Santa Cruz - UESC e do Programa de Pós Graduação em Educação em Ciências desta universidade. Tem experiência na área de Educação, com ênfase em Ensino de Ciências/Física, atuando principalmente nos seguintes temas: Práticas Freireanas no Ensino de Ciências, aproximações entre as ideias de Lev S. Vygotsky e Paulo Freire e Abordagem Temática Freireana. 